\title{
A Study of Firms' Perception of Environmental Dynamism and Innovativeness in Non-Dynamic Environments
}

\section{Patrick Tan*}

Singapore Management University, Singapore

\begin{abstract}
Managers in mature or non-dynamic industries operate under very challenging conditions and need to create competitive advantages. One potential route to do this is through innovations. This is easier said than done. Most of the studies on innovation have been concentrated in high-technology industries where the environment is highly dynamic and volatile. Limited studies have been conducted in non-dynamic environment. This study is an attempt to unravel the following research question: How does perception of environmental dynamism and pressures from competition affect firms' strategic emphasis on innovation in non-dynamic environments? Based on a survey of 164 respondents in Singapore and Hong Kong, the study explores the impact of perception of environmental dynamism and competitive pressures on innovativeness.
\end{abstract}

Keywords: Environmental dynamism; Non-Dynamic environments; Firms' perception

\section{Introduction}

Faced with disruptive forces from globalization and digitalization, innovation has become a key managerial imperative for many organizations and a topic that has attracted the attention of researchers and practitioners. Extensive theoretical and empirical studies have been conducted on firm size, incumbency, and environmental dynamism as key determinants of innovation. Most studies on innovation argued that large firm size and incumbency are major hindrance to innovativeness, and much of management thought dating back to the BCG model has suggested that the proper management tact in nondynamic, mature industries, which are characterized by slow relative growth and intense competition, is to reduce resources and reduce the investment in innovation.

If size and maturity of the industry are indeed major hindrance to innovativeness, why is it that in some industries, some firms regardless of their size, incumbency or the dynamism of the industry, continue to be innovative and perform well, while others operating in the same industry flounder and struggle to survive? Despite the relevance of this topic for both practitioners and researchers, relatively little is known about the drivers of innovativeness in environments that are non-dynamic, and about the organizational innovativeness of large global, regional and domestic firms. Most of the studies on innovation have been concentrated in high-technology industries where the environment is highly dynamic and volatile [1]. Limited studies have been conducted in non-dynamic environment [2].

This led us to ask the question "Could firms' perception of environmental dynamism and its response to competitive pressures be a determinant of innovativeness?"

This study is an attempt to unravel the following research question: How does perception of environmental dynamism and pressures from competition affects firms' strategic emphasis on innovation in nondynamic environments?

Based on a sample of 164 respondents, (105 from Singapore and 59 from Hong Kong), the study explores the impact of perception of environmental dynamism and competitive pressures on innovativeness. Results from the study suggest that the perception of environmental dynamism and competitive pressures significantly contribute to firms' innovativeness.
The remaining of the paper is organized as follows. Section 4 presents the theoretical background. Section 5 describes the data and variables. Section 4 discusses the results. The paper concludes with a summary of findings and directions for future research.

\section{Theoretical Background}

Perception of environmental dynamism and geographic scope of the firms were the two independent variables selected for this study. In mature industry, environmental conditions are generally assumed to be stable and non-dynamic. How firms perceived the dynamism of the environment and the intensity of competition may affect its innovativeness more than the actual dynamism and competitive intensity of the environment. Geographic scope was selected because it is an area that is not well studied and there remains a disparity in understanding its relationship with organizational innovativeness.

\section{Determinants of innovation}

Studies on the determinations of innovation have tended to focus on organizational context and external environment, as the two major categories of factors that are assumed to affect the innovativeness of the firm. Organizational context refers to internal characteristics of the firm, such as organization structure (e.g., centralized vs decentralized, structured vs unstructured, etc.), organizational culture (e.g., attitude towards innovation and change, risk appetite, managers' personal characteristics and tolerance for risk, etc.) that promotes or inhibits organizational innovativeness. External environment refers to the maturity and dynamism of the environment in which firms are operating in. Environmental dynamism refers to the rate and (un) predictability of changes in the environment [3-5]. This could have stemmed from competitors' actions, technological changes, regulatory changes, or changes in customers' tastes and preferences, etc. [6,7].

*Corresponding author: Patrick Tan, Singapore Management University, Singapore, Tel: 65-81688839; E-mail: patricktan@smu.edu.sg

Received March 27, 2018; Accepted April 05, 2018; Published April 15, 2018

Citation: Tan P (2018) A Study of Firms' Perception of Environmental Dynamism and Innovativeness in Non-Dynamic Environments. J Bus Fin Aff 7: 329. doi: 10.4172/2167-0234.1000329

Copyright: (c) 2018 Tan P. This is an open-access article distributed under the terms of the Creative Commons Attribution License, which permits unrestricted use, distribution, and reproduction in any medium, provided the original author and source are credited. 
"Discontinuities" may be created when any one or more of these dimensions changes disrupting the industry in the process [8].

Firms must operate in the environment which they find themselves in, and strategy and innovation cannot be developed in isolation of its environment. Utterback and Abernathy [9] argued that there is "a strong mutual relationship between a firm's choice of strategy and its environment" and that "the characteristics of the innovativeness process and of a firm's innovation attempts will vary systematically with differences in the firm's environment..." The economic environment, regardless of its dynamism, will always present opportunities for innovation [10]. As such, firms' perception of the environmental dynamism may have a greater impact on its innovativeness than the actual environment which is suggested by Wyatt. Adopting the right mindset may be a key determinant of innovativeness in firms.

\section{Firm size}

Most empirical studies suggest that, with less structure and bureaucratic administrative controls in place, small and medium-sized firms were more agile and responsive to changes in the environment. It has thus been long suggested that they were more innovative and disproportionately responsible for significant innovations [11-16].

Despite the decades of research that had been devoted to it, the disparity in arguments over the relationship between firm size and innovation remains unsettled $[17,18]$.

More recent studies suggested that, with the right capabilities, large global firms can be innovative as well. The study by Wyatt [19] showed that "far from being lumbering giants with slow reactions, several global corporations are outperforming both global and local competitors in unstable contexts by continuously repositioning and reconfiguring themselves in response to and anticipation of marketplace changes." He claims that these firms have achieved Dynamic Advantage. Knott and Vieregger argued that large firms are chief engines of innovation. Knott and Vieregger tested and indicated that "R\&D productivity, like R\&D spending, increases with firm size." There are thus compelling arguments for large firms to be innovative $[18,20]$.

\section{Perception of Environmental Dynamism}

Firms operating in the same industry faced the same environmental conditions. But, their responses to the "discontinuities" in the environment can vary significantly and is largely dependent on the cognition and decision making of its managers $[21,22]$. Drucker argued that looking at the glass as "half full" or "half empty" have very different meanings, even if it is describing the same phenomenon [23].

Studies by Dweck on mindset psychological trait suggest that individuals view intelligence, learning and its consequent effect is highly dependent on whether the person adopts a fixed or growth mindset [24]. People with fixed mindset believes they are born with innate abilities that cannot be changed or improved. People with fixed mindset dread failure because it is a negative statement on their basic abilities. On the other hand, people with growth mindset believes that they are constantly learning. They embrace failure because they realize their performance can be improved and learning comes from failure.

In firms, the organization's personality reflects the collective personality of its decision-makers or leaders. Whether the firm view the environment as dynamic or non-dynamic, is innovating or non-innovating is highly dependent on the mindset adopted by the management of the firm. Firms with a "Fixed Mindset" accept things as they are and are resistant to change. Firms with a "Growth Mindset" are constantly learning, responding and adapting to the environment. They are in a better position to sense the changes in the market and seize the opportunity to innovate.

It is thus the firms' perception of the environmental dynamism, and not the actual environment that is critical in understanding their innovativeness. Thus, we operationalized our variable in this manner. A misperception of the developments and trends in the market may result in a failure or error in applying the appropriate strategies or capabilities to address the changes.

We hypothesized that the firm's innovativeness is positively related to its perception of environmental dynamism. In other words, firms that perceive the environment as dynamic are more innovative.

\section{Research Methodology}

The focus of this study was to examine the relationship among the firm's perception of environmental dynamism, firm's geographic scope and organizational innovativeness. The subject of study is the Firm. The participants in the interviews and survey are informants, and they have been asked to inform about their current firm. The intent of this study was to analyze how innovation is viewed and takes place in nondynamic environments. There are numerous industries of this type. We selected the insurance industry for this study because it is mature and has a reputation for its stodgy conservatism. It also represented a convenient sample for reaching informants in multiple markets (Hong Kong and Singapore).

The survey questionnaire was developed and adapted from other scholarly studies. The questions on perception of environmental dynamism were adapted from a study by Baum and Wally [25], and the questions on organizational innovativeness were adapted from Nasution et al. [26].

The study involves a study on insurance companies operating in Singapore and Hong Kong. The primary data on the perceptions of the respondents on the relationships between perception of environmental dynamism and firm's innovativeness was collected through the use of structured questionnaires containing 7-point Likert scale items. The web-based self-administered survey was conducted in Singapore and Hong Kong concurrently involving 1,100 participants; 600 in Singapore and 500 in Hong Kong. The participants were randomly sourced from industry directories, personal contacts, and Singapore and Hong Kong Insurance Forum Groups on LinkedIn. The survey questionnaire was administered on Qualtrics.

Follow-up interviews were conducted with 10 participants; 5 each in Singapore and Hong Kong. The objective of the follow-up survey was to clarify and understand certain inferences drawn from the survey. None of the participants were informants in the study. The participants were randomly selected to represent the groups they belong to Table 1 .

\begin{tabular}{|c|c|}
\hline Research Questions & Hypothesis \\
\hline Does the firm size affect its perception of environmental dynamism? & Firm size is positively related to perception of environmental dynamism \\
\hline $\begin{array}{c}\text { Does the perception of environmental dynamism affect the innovativeness of } \\
\text { firms? }\end{array}$ & $\begin{array}{c}\text { Perception of environment dynamism is positively related to organizational } \\
\text { innovativeness }\end{array}$ \\
\hline
\end{tabular}

Table 1: Research questions. 


\section{Singapore and Hong Kong insurance market}

The Singapore and Hong Kong Insurance markets were chosen as they share certain similarities, and yet exhibit differences. Both Singapore and Hong Kong are mature regional financial centres with a strong legal and regulatory framework inherited from the British. Interestingly, the two markets are strong rivals in attracting international insurance groups to establish offices in their respective market.

The growth rate for Singapore and Hong Kong for 2014 and 2015 were (Table 2).

\section{Demographics and sample size}

Companies were classified as "Global," "Regional" or "Local" according to where their head office is domiciled and the extent of their overseas offices' reach. Global firms are multinational companies, mainly European and North American firms, that have offices in several countries across more than one continent. Regional firms are companies that are headquartered in Asia, mostly from Japan, China, or Hong Kong, and have one or more offices in other Asian countries. They have achieved certain scale to expand beyond their national boundaries to go regional but are not sufficiently large to expand into numerous markets in other continents. Local domestic firms are companies that are registered in either Singapore or Hong Kong only and have no overseas offices in another country outside their country of registration.

The total number of valid responses received was 102 in Singapore and 56 in Hong Kong giving us 158 responses in total. 53\% of the participants were from large global firms, $34 \%$ from regional firms and $13 \%$ from local domestic firms. This is consistent with the make-up of both the Singapore and Hong Kong market, which is dominated by large global firms. The balance is made up of mid-sized firms; i.e., Asian firms with a regional presence, and local domestic firms (Table 3 ).

The sample size for Hong Kong is smaller than Singapore due to a smaller participant base that we could access, compounded by a slightly lower response rate.

In summary, the study comprised of 11 respondents from

\begin{tabular}{|c|c|c|}
\hline & $\mathbf{2 0 1 4}$ & $\mathbf{2 0 1 5}$ \\
\hline Singapore & $8.28 \%$ & $11.2 \%$ \\
\hline Hong Kong & $6.57 \%$ & $8.2 \%$ \\
\hline
\end{tabular}

Table 2: Growth Rate - 2014 and 2015.

\begin{tabular}{|c|c|c|c|c|c|}
\hline \multicolumn{3}{|c|}{ Country } & \multicolumn{3}{|c|}{ Size } \\
\hline & & & \multirow{2}{*}{\begin{tabular}{|c|} 
Medium \\
11 \\
\end{tabular}} & \multirow{2}{*}{$\begin{array}{c}\text { Large } \\
0\end{array}$} & \multirow{2}{*}{$\begin{array}{c}\text { Total } \\
11\end{array}$} \\
\hline Singapore & Country of & Singapore Domestic & & & \\
\hline & origin & Asia (ex SG/HK) & 21 & 9 & 30 \\
\hline & & Global & 0 & 61 & 61 \\
\hline & Total & & 32 & 70 & 102 \\
\hline \multirow[t]{4}{*}{ Hong Kong } & \multirow{3}{*}{$\begin{array}{c}\text { Country of } \\
\text { origin }\end{array}$} & Hong Kong Domestic & 10 & 0 & 10 \\
\hline & & Asia (ex SG/HK) & 23 & 0 & 23 \\
\hline & & Global & 0 & 23 & 23 \\
\hline & Total & & 33 & 23 & 56 \\
\hline \multirow[t]{5}{*}{ Total } & \multirow{4}{*}{$\begin{array}{c}\text { Country of } \\
\text { origin }\end{array}$} & Singapore Domestic & 11 & 0 & 11 \\
\hline & & Hong Kong Domestic & 10 & 0 & 10 \\
\hline & & Asia (ex SG/HK) & 44 & 9 & 53 \\
\hline & & Global & 0 & 84 & 84 \\
\hline & Total & & 65 & 93 & 158 \\
\hline
\end{tabular}

Table 3: Country of origin * size * country crosstabulation.
Singapore Domestic companies, 10 respondents from Hong Kong Domestic companies, 53 respondents from Regional companies, and 84 respondents from Global companies. The actual number of companies involved would be lesser as more than one respondents could be from the same firm.

The data collected were analyzed using the SPSS 23.0 statistical program. We evaluated the relationships between the variables for reliability and correlation.

Table 4 above presents the statistics in the form of mean and standard deviation for the constructs of perception of environmental dynamism and organizational innovativeness. Cronbach's alpha was run to determine the internal consistency of the constructs. The Cronbach's alpha values of $0.786,0.745$, surpassed the recommended threshold of 0.70 (Nunnally 1978).

\begin{tabular}{|c|c|c|c|c|c|c|c|}
\hline & & Mean & S.D. & $\mathbf{1}$ & $\mathbf{2}$ & $\mathbf{3}$ & $\mathbf{4}$ \\
\hline 1 & $\begin{array}{c}\text { Perception of } \\
\text { Environment } \\
\text { Dynamism }\end{array}$ & 5.2516 & 0.72791 & $\alpha$ & & & \\
\cline { 3 - 8 } & & & $=0.745$ & & & \\
\hline 2 & $\begin{array}{c}\text { Organizational } \\
\text { Innovativeness }\end{array}$ & 5.4810 & 0.83247 & $0.540^{* *}$ & $\alpha$ & & \\
\cline { 3 - 8 } & & & & $=0.786$ & & \\
\hline
\end{tabular}

${ }^{* *}$ Correlation is significant at the 0.01 level (2-tailed).

Table 4: Results of reliability and correlational analyses.

\section{Perception of environmental dynamism and organizational innovativeness}

The construct "Perception of Environment Dynamism" was adapted from a scale originally developed by Baum and Wally and consisted of three questions [25].

- $\quad$ The pace of change in customer needs is ...

- The pace of change in competitors' strategies/action is ...

- The pace of change of technology is ...

A one-way Welch ANOVA was conducted to determine if the perception of environmental dynamism was different for groups according to their classification. Firms were classified into three groups: Domestic, Regional and Global.

The Singapore Group was classified as Domestic $(n=11)$, Regional $(n=30)$, and Global $(n=61)$. The perception of environmental dynamism score was as follows: Singapore Domestic $(M=5.2727$, $\mathrm{SD}=0.77018), \quad$ Regional $(\mathrm{M}=5.5250, \quad \mathrm{SD}=0.50151)$ and Global $(\mathrm{M}=5.0369, \mathrm{SD}=0.66275)$ and the differences between these groups were statistically significant, Welch's $F(2,26.057)=7.454, p=0.003$.

The one-way ANOVA is an omnibus test statistic. It can only tell us that at least two groups were different, but not which specific groups were significantly different from each other. Since we have three groups in our study design, and the results indicated a significant difference, we conducted further analyses on the factor to examine the differences. A Games-Howell post hoc test was conducted as a follow-up test to determine which specific groups were significantly different from each other. Games-Howell post hoc analysis revealed that the mean difference between Regional and Global (0.48811, 95\% CI [0.1895, 0.7867], $\mathrm{p}=0.001$ ) was significant. The mean difference between Global and Singapore Domestic $(\mathrm{p}=0.618)$ and Regional and Singapore Domestic $(\mathrm{p}=0.583)$ were statistically not significant.

This indicates that informants from regional firms perceived the environment as more dynamic than large global firms. In line with our 
initial discussion, regional firms are closer to the ground and able to scan and sense of what is happening in the environment better than the global firms. However, the perceptions of informants from regional firms on environmental dynamism are not significantly different from domestic firms. This may be because domestic firms are similarly close to the ground and able to scan and sense what is happening in the environment as well.

A similar test was done for the data collected in Hong Kong. The Hong Kong Group was classified as Domestic $(n=10)$, Regional $(n=23)$, and Global $(n=23)$. The perception of environmental dynamism score reported by Hong Kong informants was as follows: Domestic $(\mathrm{M}=4.8250, \mathrm{SD}=1.21364)$, Regional $(\mathrm{M}=5.8478, \mathrm{SD}=0.39700)$ and Global $(\mathrm{M}=5.0435, \mathrm{SD}=0.70167)$ and the differences between these groups were statistically significant, Welch's F $(2,19.960)=13.252$, $\mathrm{p}=0.000$. Games-Howell post hoc analysis revealed that the mean difference between Regional and Global (.80435, 95\% CI [0.3928, $1.2159], \mathrm{p}=0.000$ ) was significant. The mean difference between Global and Hong Kong Domestic ( $\mathrm{p}=0.857)$ and Regional and Hong Kong Domestic ( $\mathrm{p}=0.063)$ were statistically not significant. These findings are similar to the results for Singapore. Informants reporting on regional firms perceived the environment as more dynamic than global and local firms.

At the aggregate level, an independent sample t-test was run to determine if there were any differences in the perception of environmental dynamism between global, regional, and domestic firms in Singapore and Hong Kong. The results indicated that there was a statistically significant difference between the mean difference of all three group sizes in Singapore and Hong Kong. Global firms $(\mathrm{M}=1.03869,95 \% \mathrm{CI}[0.8934,1.1839], \mathrm{t}(83)=14.222, \mathrm{p}=0.000$. Regional firms $(\mathrm{M}=1.66509,95 \% \mathrm{CI}[1.5320,1.7982], \mathrm{t}(52)=25.111, \mathrm{p}=0.000$. Domestic firms $(M=1.05952,95 \%$ CI $[0.6016,1.5174], t(20)=4.827$, $\mathrm{p}=0.000$. Thus, the results indicated that across all levels of operating sizes, firms in Hong Kong view their environment as more dynamic than firms in Singapore.

A brief summary is as follows:

- Regional firms perceived the environment as more dynamic than Global firms and Local firms.

- Firms in Hong Kong perceived the environment as more dynamic than firms in Singapore.

Considering that the actual growth rates in Singapore are historically higher than Hong Kong, one might have hypothesized that Singapore is a more dynamic market than Hong Kong. However, our study revealed that subject in the Hong Kong firms perceived the market as more dynamic.

Our interviews revealed that Regional firms see the Asia region as their primary markets. They see their size, Asian heritage and local knowledge as advantages over global and domestic firms. Regional firms have the benefits of financial strength and a regional network to tap on, but, without having to contend with the bureaucracy found in large global organizations. The global network of large global firms can be an advantage, but it may not have been fully leveraged.

Respondents indicated that the management of domestic firms have a narrower view of the market and tend to compete mainly on lower price.

\section{Organizational innovativeness}

A one-way ANOVA was conducted to determine if organizational innovativeness was different for groups according to their classification. The organizational innovativeness score was as follows: Singapore Domestic $(M=5.1818, S D=0.94849)$, Regional $(M=5.6333, S D=0.40372)$ and Global $(\mathrm{M}=5.5213, \mathrm{SD}=0.79856)$ and the differences between these groups were statistically not significant, Welch's $\mathrm{F}(2,25.631)=1.360$, $\mathrm{p}=0.275$.

A similar analysis was conducted for the Hong Kong Group. The perceived organizational innovativeness means were as follows: Domestic ( $M=4.5200, S D=1.25857)$, Regional $(M=6.0261, S D=0.32644)$ and Global $(\mathrm{M}=5.1913, \mathrm{SD}=0.96385)$ and the differences between these groups were statistically significant, Welch's $\mathrm{F}(2,18.646)=13.461$, $\mathrm{p}=0.000$. Games-Howell post hoc analysis revealed that the mean difference between Regional and Global (0.83478, 95\% CI [0.3087, 1.3609], $\mathrm{p}=0.001$ ) was significant; and the difference between Regional and Hong Kong Domestic (1.50609, 95\% CI [0.3902, 2.6219], p=0.011) was also significant. However, the mean difference between Global and Hong Kong Domestic (0.67130, 95\% CI [-0.4975, 1.8401], p=0.319 was statistically not significant. In other words, regional firms in Hong Kong are more innovative than Global and Domestic firms.

At the aggregate level, an independent sample t-test was run to determine if there were any differences between the organizational innovativeness of global, regional, and domestic firms in Singapore and Hong Kong. Our study revealed that there was a statistically significant difference between the mean difference of all three group sizes in Singapore and Hong Kong. Global firms ( $M=1.43095,95 \%$ CI [1.2456, 1.6163], $\mathrm{t}(83)=15.359, \mathrm{p}=0.000$. Regional firms $(\mathrm{M}=1.80377,95 \% \mathrm{CI}$ $[1.6886,1.9189], \mathrm{t}(52)=31.427, \mathrm{p}=0.000$. Domestic firms $(\mathrm{M}=0.8667$, $95 \%$ CI $[0.3522,1.3811], \mathrm{t}(20)=3.514, \mathrm{p}=0.002$. The results indicated that, at all levels of operating sizes, firms in Hong Kong are perceived organizationally more innovative than firms in Singapore from the same category.

Despite the fact that Hong Kong's growth rate has been historically lower than Singapore, our findings revealed that firms in Hong Kong are organizationally more innovative than firms in Singapore. Their perception that the environment is more dynamic has spurred them to be more innovative. Some comments from the respondents were:

The senior executive of Company HK 1 commented, "Hong Kong is a very saturated market. The market is largely dominated by the big international firms. For the regional firms to grow and win market share, they need to be innovative. They are sandwiched between the big international firms and the local firms. If they didn't do things differently, they would be in trouble. Most of the local firms in HK are very small. They are either family-owned and doing in-house business or waiting to sell out. They have no ambitions to do more."

A senior executive of Company HK 4 commented, "I think it is obvious why local firms are not very innovative. In a highly competitive market like HK, small firms' hands are tied.

They are a follower rather than a leader. Regional firms are more innovative because they are in the growth phase. To grow, they need to offer things that are different from their other competitors, which is usually the big boys. The big boys can rely on Head Office for support. The regional guys don't. So, they have to innovate themselves."

One of the common themes that came up during the interviews were innovative companies proactively seeking out innovation, constantly probing what the future holds and flexibility. Innovative firms actively seek out innovation opportunities and discussing the future.

- $\quad$ Company E (a regional Asian firm) commented, "While the 
global firms try to innovate by looking for the next big thing, we prefer to unlock value at the periphery of our core business. We find there are untapped opportunities for us to innovate at the edges of our core business. It is a better utilization of our capital and the risk is much lower."

- $\quad$ Company E (a regional Asian firm) - "The world is becoming highly volatile, ambiguous and uncertain. As a group, we place a high priority in engaging with our customers, regulators, distributors. We engage with our key stakeholders regularly to update them on developments within the firm as well as to get a sense of their thinking and direction."

\section{Innovation performance}

A one-way ANOVA was conducted to determine if innovation performance was different for groups according to their firm size. Innovation performance score were as follows:

Singapore Domestic $(\mathrm{M}=4.6591, \quad \mathrm{SD}=1.59598), \quad$ Regional $(\mathrm{M}=5.2167, \mathrm{SD}=1.20520)$ and Global $(\mathrm{M}=4.4385, \mathrm{SD}=1.22019)$ and the differences between these groups were statistically significant, Welch's $\mathrm{F}(2,25.160)=4.053, \mathrm{p}=0.030$. Games-Howell post hoc analysis revealed that the mean difference between Regional and Global (0.77814, 95\% CI $[0.1292,1.4271], \mathrm{p}=0.015)$ was significant. The difference between Regional and Singapore Domestic $(0.55758,95 \%$ CI [-0.8229, 1.9381], $\mathrm{p}=0.556)$ and between Global and Singapore Domestic $(-0.22057,95 \%$ CI $[-0.1 .5674,1.1263], p=0.901$ were statistically not significant.

A similar analysis was conducted for Hong Kong Group. The perceived innovation performance score was as follows: Hong Kong Domestic $(\mathrm{M}=4.1875, \mathrm{SD}=1.75124)$, Regional $(\mathrm{M}=5.8370, \mathrm{SD}=0.82953)$ and Global $(\mathrm{M}=4.3750, \mathrm{SD}=1.2500)$ and the differences between these groups were statistically significant, Welch's F $(2,21.135)=12.727$, $\mathrm{p}=0.000$. Games-Howell post hoc analysis revealed that the mean difference between Regional and Global (1.46196, 95\% CI [0.6992, 2.2247], $\mathrm{p}=0.000$ ) was significant; and the difference between Regional and Hong Kong Domestic (1.64946, 95\% CI [0.0782, 3.2207], p=0.040) was also significant. The mean difference between Global and Hong Domestic $(0.18750,95 \%$ CI $[-1.4261,1.8011], \mathrm{p}=0.950)$ was statistically not significant.

At the aggregate level, an independent sample t-test was run to determine if there were any differences between innovation performance of global, regional and domestic firms in Singapore and Hong Kong. Our study revealed that the mean difference of Global and Regional firms in Singapore and Hong Kong was statistically significant. Global firms $(\mathrm{M}=0.42113,95 \%$ CI $[0.1561,0.6861], \mathrm{t}(83)=3.161, \mathrm{p}=0.002$. Regional firms $(\mathrm{M}=1.48585,95 \% \mathrm{CI}[1.1842,1.7875], \mathrm{t}(52)=9.885$, $\mathrm{p}=0.000$. The results indicated that at both the Global and Regional firm level, Hong Kong firms have a higher innovation performance than their Singapore counterparts. The mean difference for Domestic firms $(\mathrm{M}=0.43452,95 \% \mathrm{CI}[-0.3151,1.1841], \mathrm{t}(20)=1.209$, $\mathrm{p}=0.241)$ was statistically not significant. We attribute this to their higher perception of environmental dynamism and higher organizational innovativeness.

\section{Findings}

Our study revealed that the firm's perception of the environmental dynamism of its industry play a critical role in its innovativeness. The research results indicate a positive relationship between organizational innovativeness and perception of environmental dynamism. Firms that perceived the environment as dynamic have a higher propensity to innovate than firms that do not, even though the firms were in the same industry. In other words, innovating firms have a dynamic mindset in which they perceive of their market as dynamic.

In both Singapore and Hong Kong, our study revealed that informants of regional firms indicated that their firms saw their market as more dynamic, they were willing to innovate, and they tried to innovate more often that the informants from large global firms and local domestic firms. Regional firms perceived the environment as more dynamic than global firms and local domestic firms and are selfperceived to be organizationally more innovative.

In addition, because firms in Hong Kong perceived the environment as more dynamic than firms in Singapore, the results indicated that at all levels of operating sizes, they were perceived to be more innovative than their Singapore counterparts.

This suggests that the firm's perception of the environmental dynamism of its industry plays a critical role in their innovativeness.

When asked why we saw the results, managers interviewed reported that:

- $\quad$ SG 2 commented, "I think regional firms are more ambitious to grow. They are relatively young, most of them are probably 20 to 30 years old. They are in a hurry to make a mark for themselves. Whereas, if you look at the large multinationals, most of them have been established more than 100 years ago. Some of them have been in Asia for 100 years. They have grown quite accustomed to their share of the market. Plus, no matter what you say, at the end of the day, Singapore is only a very small part of their business. The bulk of their business is still back home in Europe or USA. Local firms lack the scale. It will get increasingly tough for them. They have to find their niche within the market or merge."

- $\quad$ SG 4 commented, "In Singapore, our local companies are bank-owned, and they focus mainly on their group businesses. When you have a god-father that feeds you business without you having to fight for it, that kills your innovative spirit. If you look at the regional firms, the situation is completely reversed. Take FWD for example. They are a new regional player. Set up about three years ago. Their owner is Richard Li, who is an entrepreneur. He is not happy with status quo. That forces his people to be innovative. Global firms don't have that kind of pressure. And it has to do with their culture and compensation."

- HK4 commented, "Regional firms are more innovative because they are in the growth phase. To grow, they need to offer things that are different from their other competitors, which is usually the big boys. The big boys can rely on Head Office for support. The regional guys don't. So, they have to innovate themselves."

\section{Implications of Findings}

Previous studies suggest that the conditions of innovation are unfavourable to large firms operating in mature industries owing to the characteristics of the industry or their firm size.

By demonstrating the effects of the perception of environmental dynamism on innovativeness, these results provide support that firms operating in non-dynamic mature industry can transcend the traditional notion that large established firms operating in mature industries are constrained by the characteristics of the industry or their firm size. The results indicate that to increase innovativeness; managers need to adopt a dynamic mindset. 


\section{Limitations}

As with any research undertaking, there are several limitations to this study because of the methodology, the sample selected and the previous research results that we reviewed.

Firstly; this study was limited to a single industry setting. A single industry was chosen as the research team was familiar with the industry and felt that it adequately represented the industry structure characteristics that we wanted to study. Single industry studies can lead to external validity problems, and the generalizability of the results may be questionable. It should be noted, however, that a within industry comparison enhances the confidence in the internal validity of the research. That is, confidence that the constructs that are being investigated are actually being directly measured. By reducing the number of industries studied, the resulting differences in the population means cannot be explained by being in different industries. Thus, reducing extraneous variables increases internal validity Additionally, we had no reason to believe that the industry chosen was in any way unique such that the results cannot be generalized. We expect that these findings will be useful to the fields of innovation and competitive strategy in a mature market. It may be useful to extend future studies to include other mature industries, such as airlines, banks, healthcare, and others.

Secondly, this study was geographically limited to Singapore and Hong Kong only. Singapore and Hong Kong were selected as they share certain similarities, and yet exhibit differences. The research team was familiar with the industry and felt that it adequately represented industry structure characteristics that we wanted to study. The sample size was limited due to the number of firms in the market and the accessibility to management informants. Limiting the study to Singapore and Hong Kong can lead to external validity problems, and the generalizability of the results may be hampered. However, we had no reason to believe that the two geographies chosen were in any way unique such that the results could not be generalized. We expect that these findings will be useful to the fields of innovation and competitive strategy in a mature market. Future research might expand the geographical scope to include multiple countries and with a larger sample size, or to provide a longer period for informants to respond.

Thirdly, to generate useful and reliable data for a between-group study, a large number of participants is often required. The number of participants in our study was limited due to the number of firms in the market and the accessibility to management informants. In addition, unequal sample sizes can affect the homogeneity of variance assumption. The unequal sample size between domestic, regional and global firms; and between Singapore and Hong Kong may affect the homogeneity of variance assumption and produce unreliable results and obscure genuine patterns and trends. However, we had no reason to believe this to be the case. We had used Welch's ANOVA to compare the means. Welch's ANOVA is more robust than one-way analysis of variance (ANOVA) and maintains type I error rates close to nominal for unequal variances and for unequal sample sizes. It may be useful to extend future studies to include a larger and better-balanced sample size.

Fourthly, this study was a first attempt to understand the firm's perception of environmental dynamism and its effect on innovativeness in mature industry. It was a macro-level study with macro concepts. Future studies will need to examine each of the constructs at a more granular level.

Finally, the level of people interviewed and surveyed as part of the study was determined and chosen by the researcher based on the title or designation of the participants. Even though the researcher controls for the management level of the participants being studied through their job title or designation, the lack of control over other factors, such as job role, seniority within the firm or knowledge about the innovativeness of their firm, can affect the reliability of the study. We had no reason to believe the reliability of the study was affected in any way as our respondents were randomly selected and comprised of management-level staff.

\section{Recommendations for Future Research}

As pointed out above; future studies could be extended to include other non-dynamic, mature industries, a wider geographic scope and employ an enlarged sample size. This study was a first attempt to understand the firm's perception of environmental dynamism and its effect on innovativeness in a non-dynamic environment. This research was a macro-level study investigating rather macro concepts. Future studies will need to study the constructs at a micro and granular level.

\section{Concluding Remarks}

The purpose of this study was to address the question of whether large firms in mature industries have a source of advantage that enables them to be innovative, and to gain a better understanding of how such firms approach innovation. Throughout this research journey, there were a number of insights gained, and exceptions found.

Our study indicates a positive relationship exists between the perception of environmental dynamism, organizational innovativeness, and innovation performance. Firms that perceived the environment as dynamic have a competitive advantage that enables them to have a higher propensity to innovate. In summary, it appears that one of the most significant barriers to innovation resides in the firm's own management and their ability to conceive of their market and environment as dynamic. Much like the work of Wyatt (2015), this study indicates that the management perceptions of firms working in the same industry are very different. That is, where some see a static stodgy industry other see a dynamic environment ripe for innovation.

Similarly, while we began this research under the guise that the firm size mattered, we see evidence that it is size as well as the geographic orientation of the firm. Firms that were wholly domestic showed little impetus to innovate while firms that were regional in nature demonstrated the highest willingness to undertake innovations. This insight came out in the quantitative analysis and was further amplified in the interviews as managers related stories of the aggressive regional players and their desires to grow. This would seem wholly logical as firms that move beyond their borders are generally in some way more expansive in their business models. The management orientation to the market, as they choose to move beyond their comfortable home markets is one of expansion and a willingness to confront the different.

Overall, this study is a step towards developing a more thorough understanding of innovation in mature industries. From the quantitative analysis and the insights gained from the interviews with managers, we would offer the following prescriptive advice to managers operating in mature markets. Even though the mature industry enjoys some level of stability because of its industry structure, the pace of change in the industry is not a given. It is rather a dynamic environment if treated as such. In essence, in reacting with its environment, the firm often has the ability to drive the environment. Companies operating in mature industries need not throw in the towel and give up on growth opportunities through innovation. In referencing back to the work of Bock and George (2014), the business model innovations are often still 
Citation: Tan P (2018) A Study of Firms' Perception of Environmental Dynamism and Innovativeness in Non-Dynamic Environments. J Bus Fin Aff 7: 329. doi: 10.4172/2167-0234.1000329

very much within reach. Firms may need to reconfigure its resources, and the path may not always be clear-cut. But there are opportunities for those that venture forward.

First and foremost, management needs to overcome its perception problem by adopting a dynamic growth mindset and looking beyond the horizon to see what others are unable to see. Regardless of good or tough times, opportunities for innovation may indeed always be there. Those that see the market as dynamic are more likely to be able to see opportunities and pursue innovation.

Secondly, a healthy dose of pressure and curiosity can drive companies to be more innovative. Pressure keeps the innovative companies on their alert and constantly exploring, searching, creating and exploiting opportunities in the market. Market driven curiosity pushes the team to keep asking "Is there a better way of doing things?" The Hong Kong market was reported by informants to be more innovative, and they indicated that the firms perceived the market as both dynamic and competitive. Hence, we see more innovative perceptions and activities indicating that innovation is sought.

Thirdly, innovation is a discipline. Innovative companies have a distinct philosophy towards innovation and risk-taking; they have the right people with the right mindset in place, and they strive to remain flexible in their structures and processes to be responsive to changes.

Last but not least, it appears that innovative companies are not content with simply responding to market changes. They are entrepreneurially oriented and seek to influence and drive the changes in the market.

The author hopes the findings of this study will help managers understand the importance of their firm's perception of its environmental dynamism as well as pave the way for more comprehensive research on this matter.

\section{Ethical Approval}

All procedures performed in studies involving human participants were in accordance with the ethical standards of the institutional and/ or national research committee and with the 1964 Helsinki declaration and its later amendments or comparable ethical standards.

\section{Informed Consent}

Informed consent was obtained from all individual participants included in the study.

\section{References}

1. Audia PG, Goncalo JA (2007) Past success and creativity over time: A study of inventors in the hard disk drive industry. Manage Sci 53: 1-15.

2. Caiazza $R$ (2015) Explaining innovation in mature industries: Evidences from Italian SMEs. Technol Anal Strateg 27: 975-985.

3. Dess GG, Beard DW (1984) Dimensions of organizational task environments. Adm Sci Q 29: 52-73.
4. Boyd BK, Dess GG, Rasheed AMA (1993) Divergence between archival and perceptual measures of the environment: Causes and consequences. Acad Manage Rev 18: 204-226.

5. Donaldson $L$ (2001) The contingency theory of organizations. Sage publications, Australia.

6. O'Sullivan D, Dooley L (2009) Defining objectives. Applying Innovation.

7. Jordan EA (2010) The Semiconductor Industry and Emerging Technologies: A Study Using a Modified Delphi Method. ERIC.

8. Tushman ML, Anderson P (1986) Technological discontinuities and organizational environments. Adm Sci Q 31: 439-465.

9. Utterback JM, Abernathy WJ (1975) A dynamic model of process and product innovation. Omega 3: 639-656

10. Malik N, Aminu M (2011) The role of human resource in new globalized world. Guidelines for Submission of Articles pp: 171.

11. Pavitt K, Wald S (1971) The conditions for success in technological innovation, Organisation for Economic Co-operation and Development. SwissRe (2016) SIGMA 3-2016.

12. Pavitt K (1987) The size distribution of innovating firms in the UK: 1945-1983. J Ind Econ 35: 297-316.

13. Acs ZJ, Audretsch DB (1988) Innovation in large and small firms: An empirical analysis. Am Econ Rev 78: 678-690.

14. Acs ZJ, Audretsch DB (1990) Innovation and small firms. Mit Press.

15. Acs ZJ, Audretsch DB (1991) R\&D, firm size and innovative activity. Innovation and technological change: An international comparison 98: 451-456.

16. Nooteboom B (1994) Innovation and diffusion in small firms: Theory and evidence. Small Bus Econ 6: 327-347.

17. Hamilton AL (2012) Exploring Identity and Organizing for Sustained Innovation in an Entrepreneurial Academic Laboratory: Two Grounded Theory Models. Smeal College of Business.

18. Knott AM, Vieregger C (2016) Reconciling the Firm Size and Innovation Puzzle. US Census Bureau Center for Economic Studies.

19. Wyatt SR (2015) Dynamic Advantage. Singapore Management University, Singapore.

20. Knott AM, Vieregger C (2015) All Hail Large Firm Innovation: Reconciling the Firm Size and Innovation Debate.

21. Tripsas M, Gavetti G (2000) Capabilities, cognition, and inertia: Evidence from digital imaging. Strategic Manage J 21: 1147-1161.

22. Drucker PF (2002) The discipline of innovation. Harvard Business Review 80 95-102.

23. Dweck CS (2000) Self-theories: Their role in motivation, personality, and development. Psychology Press.

24. Baum J, Wally S (2003) Strategic decision speed and firm performance. Strategic Manage J 24: 1107-1129.

25. Nasution HN, Mavondo FT, Matanda MJ, Ndubisi NO (2011) Entrepreneurship: Its relationship with market orientation and learning orientation and as antecedents to innovation and customer value. Industrial Marketing Management 40: 336-345.

26. Nasution HN, Mavondo FT, Matanda MJ, Ndubisi NO (2011) Entrepreneurship: Its relationship with market orientation and learning orientation and as antecedents to innovation and customer value. Industrial Marketing Management 40: 336-345 